\title{
Diálogos epistolares e edição: intercâmbios intelectuais entre Brasil e Argentina na correspondência de Ricardo Levene e Pedro Calmon
}

\author{
Nayara Galeno do Vale ${ }^{1}$
}

Resumo: Este artigo propõe-se pensar as relações estabelecidas pelo argentino Ricardo Levene e o brasileiro Pedro Calmon na década de 1930, por ocasião das iniciativas de aproximação entre os governos de seus países. Fazem parte desse diálogo também as instituições das quais os referidos intelectuais faziam parte em seus respectivos países e o papel da escrita e do ensino de História no desenvolvimento dessas relações. As principais fontes serão as correspondências trocadas entre Calmon e Levene que abordaram seus projetos intelectuais em comum. Tais projetos tratavam-se, sobretudo, das bibliotecas de autores traduzidos em seus respectivos países: a Biblioteca de Autores Brasileños traducidos al castellano e a Coleção Brasileira de Autores Argentinos. Ambos os empreendimentos editoriais foram realizados por meio de convênios de tradução que visavam à cooperação intelectual entre Brasil e Argentina e representaram importantes iniciativas no que diz respeito à diplomacia cultural celebrada entre os dois países.

Palavras-chave: Pedro Calmon; Ricardo Levene; correspondência intelectual

\section{Epistolary dialogues and editing: intellectual exchanges between Brazil and Argentina in the correspondence of Ricardo Levene and Pedro Calmon}

\begin{abstract}
This study proposes a reflection on the relations established by the Argentinian historian, Ricardo Levene, and Brazilian historian, Pedro Calmon, in the 1930s, during initiatives aimed at strengthening ties between the governments of their countries. This dialogue also includes the institutions of which these intellectuals were members and the role of writing and history teaching in the development of these relations. The main source of information was the correspondence exchanged between Calmon and Levene discussing their common intellectual projects. Such projects were mainly concerned in translating collections of works by national authors and included the 'Library of Brazilian Authors Translated into Spanish' (Biblioteca de Autores Brasileños Traducidos al Castellano, title in Spanish) and the 'Brazilian Collection of Argentinian Authors' (Coleção Brasileira de Autores Argentinos, title in Portuguese). Both editorial enterprises were carried out through translation agreements aimed at an intellectual cooperation

${ }^{1}$ Doutora em História pela Universidade Federal Fluminense. Professora da Prefeitura da Cidade do Rio de Janeiro. Atualmente desenvolve a pesquisa intitulada "Identidade do historiador e embates em torno da escrita da História do Brasil na obra de Pedro Calmon”. E-mail: nayaraghist@gmail.com.
\end{abstract}


between Brazil and Argentina, and represented important cultural diplomacy initiatives between the two countries.

Keywords: Pedro Calmon; Ricardo Levene; intellectual correspondence

Artigo recebido em: 30/06/2020

Artigo aprovado para publicação em: 07/09/2020

Felicitaciones muy efusivas. - Ha sido Vd. designado académico correspondiente en el Brasil por unanimidad de votos. - Es un homenaje que la Academia Nacional de la Historia ha tributado al eminente historiador del Brasil y al espírito representativo de la cultura de esa pátria amiga, que es Pedro Calmón. (BR BACMB PC TXT AA 05_4200)

O fragmento acima faz parte de uma carta enviada pelo intelectual argentino Ricardo Levene ao intelectual brasileiro Pedro Calmon em julho de 1938. Ela é expressiva do reconhecimento buscado pelo intelectual brasileiro como historiador e como um cultor das relações entre seu país e o país vizinho, a Argentina. Este artigo propõe tratar das relações estabelecidas por Levene e Calmon na década de 1930, por ocasião das iniciativas de aproximação entre os governos de seus países e as instituições das quais faziam parte, bem como o papel da escrita e do ensino de história no desenvolvimento dessas relações.

Ao analisar os diálogos que se estabeleceram entre o Brasil e a Argentina em torno da produção histórica entre as décadas de 1910 e 1940, Ana Paula Barcelos Ribeiro da Silva aponta que tais diálogos, muito profícuos nas primeiras décadas do século XX, foram motivados por uma releitura do passado em ambos os países. Tal releitura promoveu a positivação do passado colonial e a atuação das metrópoles católicas Portugal e Espanha no processo de colonização e contribuiu para fomentar um clima de cordialidade regional, calcada na compreensão e no conhecimento recíprocos. (SILVA, 2011)

As análises da autora partem do pensamento e da interlocução entre historiadores brasileiros e argentinos como representantes (e ao mesmo tempo representativos) de instituições de seus países que visavam difundir uma versão da história nacional 
legitimada por um trabalho de pesquisa documental. Dessa forma, os nomes de Pedro Calmon e Ricardo Levene se destacam como figuras-chave na representação de seus países nos empreendimentos de aproximação regional que foram levados a cabo nas décadas de 1930 e 1940.

A autora afirma que os historiadores em questão veiculavam uma pretendida "história oficial", pois seus trabalhos e trajetórias estavam ligados a instituições que faziam parte da estrutura dos Estados brasileiro e argentino, como é o caso do Instituto Histórico e Geográfico Brasileiro (IHGB) e a Junta de Historia y Numismática Americana, que a partir de 1938, por decreto do Poder Executivo se tornou Academia Nacional de la Historia Argentina. (SILVA, 2011, p. 81)

Gustavo Sorá (2003, p. 25), ao tratar das traduções de autores brasileiros na Argentina, afirma que no Brasil, em meados da década de '30, se criaram instituições estatais específicas voltadas ao que denomina de promoção de uma "cultura nacional autêntica". Em paralelo, algumas editoras, graças à especialização do setor, conseguiram promover a distribuição de livros em escala nacional. Tais dimensões, segundo o autor, impulsionaram a formação de um "circuito de reconhecimento" importante para a trajetória editorial de autores consagrados como "descobridores da brasilidade" na década de 1930. A difusão nacional de um livro é um fator decisivo para que ele e seu autor sejam "descobertos" e traduzidos no exterior como representativos da "cultura escrita do país". (SORÁ, 2003, p. 26-27)

Apesar de tratarem de temáticas diferentes, tanto Sorá (2003) quanto Silva (2011) mostram a importância do Estado brasileiro no estabelecimento de relações com a Argentina e na seleção do que deveria ser autorizado a ser apresentado no país vizinho como "legitimamente" brasileiro. Ainda que os governos dos países tenham trabalhado de maneira intensa para promover a cooperação, deve-se considerar que os Estados brasileiro e argentino não atuaram exclusivamente na promoção das relações internacionais.

As relações culturais entre Brasil e Argentina foram intensificadas como parte dos esforços de aproximação empreendidos por diversos agentes culturais, fossem essas 
iniciativas espontâneas ou parte de projetos patrocinados pelo Estado em ambos os países. Torna-se relevante considerar as relações culturais em toda a sua complexidade e para isso, é imprescindível considerar a atuação dos agentes culturais como os intelectuais mencionados nos projetos de cooperação. (SANTOS, 2009)

Ao investigar as trocas culturais e intelectuais no espaço latino-americano nas décadas de 1930 e 1940, Eliana de Freitas Dutra (2012, p. 2) mostra que o livro era considerado "uma ferramenta de propaganda, de aproximação diplomática e de divulgação da cultura e da civilização brasileiras no exterior”. Pretendia-se que os livros, bem como os intelectuais, circulassem como vetores das ideias de cultura e identidade brasileiras que se desejava difundir no país vizinho. Nesse contexto, Pedro Calmon é homenageado na Academia Nacional de la Historia e reputado como um "espírito representativo da cultura" brasileira.

Este artigo explora a correspondência trocada entre Calmon e Levene tratando dos seus projetos em comum, sobretudo as coleções de autores traduzidos em seus respectivos países, que foram inauguradas por livros dos dois autores. ${ }^{2}$ Trata-se da Biblioteca de Autores Brasileños traducidos al castellano, que teve como primeiro volume a Historia de la civilizacion brasileña, livro de Pedro Calmon traduzido e publicado em Buenos Aires em 1937 e Coleção Brasileira de Autores Argentinos, que teve como primeiro volume a obra de Levene Síntese da História da Civilização Argentina, publicada em 1938, no Rio de Janeiro.

Ambas as iniciativas editoriais foram realizadas por meio de convênios editoriais de tradução celebrados entre os dois países, visando à cooperação intelectual, podendo instigar a observância da constituição de redes e sociabilidades intelectuais. Para além da consideração da História Intelectual na América Latina como unicamente uma "história do pensamento e o debate de ideias e ideologias", como aponta Kátia Baggio, estudos vêm mostrando a importância de mapear as relações, as disputas e as circulações de

\footnotetext{
${ }^{2}$ Agradeço a Ana Paula Barcelos Ribeiro da Silva por ter compartilhado comigo alguns de seus achados no arquivo de Ricardo Levene, incluindo duas cartas de Pedro Calmon ao intelectual argentino. Agradeço ainda a Giselle Martins Venancio por ter me dado preciosas indicações bibliográficas sobre o trabalho com correspondência intelectual.
} 
ideias, pessoas e impressos entre o Brasil e os países hispano-americanos. (BAGGIO, 2014, p. 599) Nesse sentido, a correspondência entre intelectuais brasileiros e hispanoamericanos pode se constituir como fonte singular e privilegiada para mapear as redes de sociabilidade que se estabeleceram entre intelectuais na América Latina.

Jorge Meyers (2014, p. 54) afirma que mais que um meio de comunicação, embora sem perder esse caráter, a correspondência possui um caráter polissêmico, podendo também ser uma expressão das atividades públicas dos intelectuais. Segundo o autor, por meio da correspondência também se faz possível rastrear a evolução da obra de um intelectual, as mudanças de posição, mapear seu universo de interlocução e saber da existência de projetos nunca concretamente realizados, mas que tiveram sua importância para a trajetória da figura investigada. (MEYERS, 2014, p. 66)

A correspondência a ser analisada neste trabalho faz parte dos acervos da Biblioteca Nacional de Maestros, em Buenos Aires, que guarda o arquivo de Ricardo Levene $^{3}$ e do Centro de Memória da Bahia, em Salvador (BA) órgão da Fundação Pedro Calmon que guarda o arquivo pessoal do seu titular. ${ }^{4}$

As trocas de correspondência entre Ricardo Levene e Pedro Calmon se iniciaram na segunda metade da década de 1930, quando Calmon era professor universitário e membro de importantes instituições do campo intelectual brasileiro e um historiador reconhecido, ainda que jovem. Ao todo, são vinte cartas de Levene endereçadas a Pedro Calmon. Em contrapartida, foram encontradas apenas três cartas de Pedro Calmon endereçadas a Ricardo Levene.

Ao trabalhar com um tipo específico de correspondência do intelectual brasileiro Oliveira Vianna - aquela escrita por pessoas que receberam livros de Vianna como presentes - Giselle Venancio afirma que a "prática epistolar de um indivíduo só existe em função de um outro, para quem se enuncia uma fala e de quem se aguarda uma

\footnotetext{
3 Uma parte do acervo encontra-se digitalizada e disponível na internet no domínio http://www.bnm.me.gov.ar/catalogos/. A consulta aos documentos físicos do acervo de Ricardo Levene encontra-se suspensa por tempo indeterminado.

${ }^{4} \mathrm{O}$ fundo de Pedro Calmon guarda 19.398 documentos textuais e 2.343 documentos iconográficos e contém principalmente correspondências datadas das décadas de 1930 a 1980. Para mais informações Cf: http://www.fpc.ba.gov.br/modules/conteudo/conteudo.php?conteudo=80
} 
resposta." (VENANCIO, 2001, p. 22-23). Provavelmente, a maior parte das cartas de Levene foi respondida por Calmon, entretanto, por algum motivo, as respostas não foram preservadas no arquivo do destinatário. Foi possível encontrar no fundo de Levene correspondências de intelectuais brasileiros como Afonso Taunay, o que pode denotar que as cartas de Calmon talvez não tenham sido vistas como dignas de serem guardadas pelo argentino.

A "sabotagem da correspondência" realizada por um dos correspondentes e apontada por Geneviève Haroche Bouzinac é apenas um dos obstáculos com o qual o historiador que escolhe trabalhar com esse tipo de fonte pode se deparar e que tornam o trato com a fonte epistolar muito desafiador. (HAROCHE-BOUZINAC, 2016, p. 184) Por esse motivo, e por outros, a autora aponta que para utilizar a carta como documento é necessário que ela seja "objeto de confrontações". (HAROCHE-BOUZINAC, 2016, p. 15) Dessa forma, busca-se aqui confrontar a correspondência entre Levene e Calmon com outras fontes, de forma que se possa preencher algumas lacunas, dentre elas, a falta das respostas possivelmente dadas às cartas do brasileiro.

\section{Trajetórias intelectuais cruzadas}

Ricardo Levene nasceu em 1885 em Buenos Aires. Formado em Direito pela Universidad de Buenos Aires (1906), foi professor da Universidad Nacional de La Plata, na qual chegou a ocupar o posto de presidente entre os anos de 1930-1931 e 1932-1935. Na mesma universidade exerceu também o posto de Decano da Faculdade de Humanidades. (LOPES, 2017, p. 387) Foi também membro da Junta de Historia y Numismática Americana desde o ano de 1915. A instituição se transformou na Academia Nacional de la Historia em 1938. Levene foi presidente da Junta entre os anos de 1927 e 1931 e 1934 e 1938 e da Academia Nacional de la Historia até 1959, ano de sua morte. (BEIRED, 2009, p. 48)

Com tantos cargos e títulos em seu currículo, Levene estava referendado como representante privilegiado dos historiadores de seu país, assentado em uma sólida rede institucional tecida tanto no interior, quanto no exterior. Portanto, mostrava-se como uma 
figura exemplar de um Estado que buscava a história como um mecanismo de legitimação. (SUÁREZ e SAAB, 2011, p. 214)

Pedro Calmon nasceu na cidade de Amargosa, no estado da Bahia, em 1902. Migrou para o Rio de Janeiro em 1922, tendo também se formado em Direito (1924) pela Faculdade de Direito da Universidade do Rio de Janeiro. Foi professor da mesma universidade, tornando-se livre docente em 1934 e catedrático em 1938. No mesmo ano, a Faculdade de Direito transformou-se na Faculdade Nacional de Direito da Universidade do Brasil e Calmon tornou-se diretor da mesma, cargo que ocupou até 1948, quando saiu para ocupar a reitoria da Universidade do Brasil por sucessivos mandatos quase ininterruptos, até o ano de 1966.

Na década de 1920, Levene cultivara relações com o Brasil, sobretudo com intelectuais ligados ao Instituto Histórico e Geográfico Brasileiro (IHGB). Max Fleiuss, secretário perpétuo da instituição lhe escrevera em 12 de abril de 1921, pedindo que aceitasse o convite para participar do Congresso de História da América, que seria realizado no Instituto Histórico e Geográfico Brasileiro no ano seguinte, e que fosse representante da comissão organizadora na Argentina. Em 1922, Levene foi indicado por Fleiuss e se tornou membro correspondente do IHGB. Em retribuição, Levene indicou Fleiuss, juntamente a outros brasileiros para membros correspondentes da Junta de Historia y Numismática Americana. (SILVA, 2011, p. 94)

Levene e Calmon participaram do Congresso Internacional de História da América, que se realizou na semana de 7 a 15 de setembro de 1922, em comemoração ao centenário da independência do país. Buscava-se com o evento celebrar a amizade entre os países vizinhos. (GUIMARÃES, 1997) Levene foi delegado especial da República Argentina ao congresso de 1922, como decano da Faculdade de Ciências e Educação da Universidade de La Plata. Em entrevista concedida ao jornal La Razón após a participação no Congresso, informou ter frequentado quase que diariamente o IHGB no período em que esteve no Brasil, assim como o Colégio da Ordem dos Advogados e a Academia Brasileira de Letras, instituições representativas do campo intelectual brasileiro às quais Pedro Calmon ulteriormente ascenderia. (SILVA, 2011, p. 96) 
A realização do Congresso de História da América representa um marco no estabelecimento de relações com outros países do continente. Estava em questão a superação da construção a respeito da memória nacional concebida pelo Instituto no decorrer do século XIX, que privilegiava a fundação da nacionalidade brasileira em bases fornecidas apenas pelo legado europeu. (GUIMARÃES, 1997, p. 222) Os proponentes do evento pretendiam, além de promover um congraçamento intelectual entre os representantes das nações americanas, projetar um passado partilhado que promovesse uma comunhão entre o Brasil e os demais países do continente. (GUIMARÃES, 2005, p. 194)

Em 1922, Pedro Calmon era considerado um jovem e promissor historiador. Levado pelas mãos do padrinho, que era sócio efetivo da instituição, adentrou o Instituto Histórico e Geográfico Brasileiro em 1922, como proponente de três teses ao Congresso Internacional de História da América. Seu padrinho, o engenheiro e político Miguel Calmon du Pin e Almeida, o convidara para morar no Rio de Janeiro com a promessa de um cargo para secretariar os preparativos dos festejos da Independência. A despeito de sua participação no congresso, Pedro Calmon só seria aceito como sócio efetivo no IHGB, em 1931, quase 10 anos depois.

Na década de 1930, Calmon se distanciara da figura do jovem inexperiente que chegara ao Rio de Janeiro em 1922 e buscava seu "lugar ao sol". Foi indicado por seu padrinho ao cargo de conservador do Museu Histórico Nacional e em 1936, tornou-se membro da Academia Brasileira de Letras (ABL), com apenas 34 anos. Tornou-se orador do Instituto Histórico e Geográfico Brasileiro (IHGB) em 1938 e chegou à presidência da instituição no ano de 1968, cargo que ocupou até a sua morte, em 1985.

A partir dessas breves descrições, pode-se perceber que as trajetórias dos dois intelectuais são semelhantes, embora tenham se desenvolvido em tempos e espaços diferentes. Ambos eram formados em Direito, mas se dedicaram ao estudo e à escrita da História, tiveram uma atuação importante nos meios universitários de seus respectivos países e em instituições ligadas ao poder público, que visavam produzir uma história 
nacional que tivesse estatuto de verdade conferido a partir da pesquisa documental. (SILVA, 2012, p. 215)

A questão é o que levou a obra de Pedro Calmon a ser equiparada à de Ricardo Levene para inaugurar as coleções de autores brasileiros e argentinos, uma vez que ele, apesar de fazer parte de instituições reconhecidas do campo intelectual brasileiro como o IHGB e a ABL, era muito mais jovem que seu congênere do país vizinho.

As obras de ambos os historiadores são qualificadas nas análises que se fazem a seu respeito como "oficiais", embora não se explique claramente o que isso significa. Em linhas gerais, define-se a história oficial como uma historiografia que considera como atores principais o Estado e as elites. Outra definição possível, seria considerar como oficial uma historiografia que visa defender os interesses de um governo, uma instituição ou uma figura relevante.

As escritas da história de Calmon e Levene eram produzidas no âmbito de instituições que recebiam subvenção estatal e seus discursos se coadunavam ao que os governos buscavam veicular como fonte de legitimação. Entretanto, mais que identificar seus escritos como "oficiais", busca-se compreender o motivo de seus escritos terem encontrado ressonância respectivamente em seus países e nos países aos quais se reportavam em busca de estabelecer relações. Busca-se ainda compreender de que forma as relações que estabeleceram como representantes dos seus países qualificava as interpretações presentes em suas obras como uma introdução para a história de suas nações junto à nação estrangeira com o qual se relacionavam.

Parte-se do pressuposto de que a correspondência entre os intelectuais pode ajudar a complexificar os meandros das empreitadas estatais à frente dos quais estiveram os dois intelectuais referidos. Geralmente, os estudos que se debruçaram sobre os empreendimentos em questão se utilizaram prioritariamente de documentação dos Ministérios das Relações Exteriores do Brasil e da Argentina. Por esse motivo, o diálogo epistolar pode ajudar a compreender as interlocuções em torno de iniciativas que partiram dos governos, mas que foram materializadas por pessoas que ocupavam posições intelectuais relevantes em suas pátrias. (GOMES, 2004, p. 54) 
Pierre Bourdieu define o campo científico como "um microcosmo social, parcialmente autônomo em relação às necessidades do macrocosmo no qual se encontra inserido". (BOURDIEU, 2022, p. 144) Ao considerar o campo das ciências sociais, Bourdieu afirma que ele deve ser tratado de forma diferente da dos outros campos científicos, pois opera a partir de lógicas opostas: a do campo político, no qual "a força das ideias depende sempre da força dos grupos que as aceitam como verdadeiras" e a do campo científico.

Em sua visão, o campo das ciências sociais se fundamenta a partir dessas duas vertentes opostas, às quais os produtores podem se dirigir em busca de legitimação, mas que possuem princípios de hierarquização e de validação incompatíveis. O autor aponta que a ignorância da lógica específica dos campos científicos promove uma "redução" ao político, no sentido de anular os pesquisadores na sua condição de cientistas, transformando-os em "simples" militantes. (BOURDIEU, 2002, p. 158)

Apesar de não estar tratando do campo das ciências sociais no Brasil como um todo, o presente estudo trata das relações que a escrita da história estabelece com as demais ciências sociais, em um momento em que os campos acadêmicos de produção das chamadas Ciências Humanas estavam em processo de delimitação e no qual os intelectuais que se dedicavam ao estudo e à escrita da História eram considerados "homens de letras".

No Brasil, nas primeiras décadas do século XX, os historiadores, como homens de letras, individualmente ou reunidos em instituições, empreendiam calorosos debates visando definir o que poderia ser considerada uma história "moderna". As discussões passavam pela consideração de que para adquirir um status de cientificidade, a história deveria dialogar com as chamadas ciências sociais, sobretudo com a sociologia, vista como a ciência "rainha" naquele momento. (GOMES, 2009, p. 9)

O estabelecimento de um corpo de saberes e de um perfil profissional mobilizava os que se dedicavam à escrita da história. Ângela de Castro Gomes aponta a existência de uma forte ligação entre o delineamento de um saber erudito e sua utilidade pedagógica ou pragmática. Os que escolhiam se dedicar à história - ou em suas percepções, eram 
escolhidos por ela - viam-se como imbuídos da responsabilidade de desenvolver e reforçar o amor pela pátria dentre os imaginados cidadãos. São destacadas pela autora as relações de tais intelectuais com a educação, por meio da escrita de compêndios que, embora não fossem produzidos com a finalidade de utilização em sala de aula, tinham um fim claramente pedagógico. (GOMES, 2009, p. 10-11)

No Brasil, o Instituto Histórico e Geográfico Brasileiro desempenhou um importante papel na fundação dos estudos históricos, tanto no que concerne à produção de um conhecimento erudito, instituído com base em regras de elaboração consideradas científicas, quanto no que diz respeito ao projeto pedagógico de elaboração de uma consciência nacional por meio de um passado comum. (FERREIRA, 2013, p. 9)

Considerando o alerta de Bourdieu, propõe-se considerar a categoria dos intelectuais de maneira mais complexa, não como "militantes" que atuavam exclusivamente a serviço da legitimação do Estado por meio da escrita de uma história oficial. Nesse sentido, a categoria de "mediadores" culturais, pensada por Jean-François Sirinelli, pode ajudar. (SIRINELLI, 2003, p. 242)

Objetiva-se chamar a atenção para as "práticas de mediação cultural" desenvolvidas por Pedro Calmon ao transitar entre o campo intelectual e, mais especificamente, entre o domínio da escrita da história do Brasil e o campo político. (GOMES e HANSEN, 2016, p. 9)

Ao conseguir se firmar como membro de estratégicas instituições do campo intelectual brasileiro, Pedro Calmon atuou de um lugar privilegiado na rede de sociabilidade da qual fazia parte para se tornar uma peça fundamental de um projeto de mediação cultural que possibilitou diálogos entre o Brasil e a Argentina. Projeto este que possuía um caráter político oficial, mas que se consolidou por meio da circulação de ideias em redes intelectuais, que materializaram projetos no âmbito cultural, como as comissões de revisão e os convênios editoriais. 


\section{Projetos de revisão e comissões em correspondências intelectuais}

No período da Primeira República, a partir da chave do pan-americanismo, movimento delineado por meio de um conjunto de projetos que visavam ao incentivo à aproximação dos países da América sob a liderança dos Estados Unidos, iniciativas diplomáticas foram levadas a cabo para promover a aproximação entre o Brasil e os demais países sul-americanos.

Nas primeiras décadas do século XX, com o Barão do Rio Branco à frente da pasta das relações exteriores, um empreendimento intelectual ganhou destaque no contexto cultural brasileiro, no sentido da aproximação intracontinental: a Revista Americana. O projeto da publicação partiu da alta cúpula do Ministério das Relações Exteriores. O periódico foi publicado entre 1909 e 1919 e reuniu textos de intelectuais brasileiros e sulamericanos com o objetivo de constituir um projeto de identidade brasileira integrada ao continente. (CASTRO, 2007, p. 20)

Quando o Barão do Rio Branco assumiu a presidência do IHGB, em 1908 - cargo que ocupou por curto período, até 1912 - algumas temáticas foram postas em outros termos no interior da instituição. Uma dessas questões foi a que diz respeito às relações entre o Brasil e os outros países americanos. Uma conduta institucional de cautela em relação aos países vizinhos e avessa a qualquer forma de aproximação deu lugar a uma postura de empolgação em relação a uma almejada solidariedade americana. (SILVA, 2019, p. 17)

À presidência do Barão do Rio Branco na instituição, seguiu-se a do Conde Afonso Celso, que continuou a escalada das "relações interamericanas" como um "programa de trabalho". A ideia de realizar um Congresso Internacional de História da América para comemorar o centenário da Independência do Brasil, a se realizar em 1922, surgiu em meio aos trabalhos do Primeiro Congresso de História Nacional, reunido em setembro de 1914. (GUIMARÃES, 1997, p. 221-222)

A realização do Primeiro Congresso de História da América representou uma mudança de padrão em relação a uma memória nacional fabricada e cristalizada no 
interior da própria instituição no decorrer do século XIX. Tal construção apontava para a herança europeia como única constituidora da identidade nacional brasileira, em negação ao pertencimento americano. (GUIMARÃES, 1997, p. 222)

Às nações vizinhas foi imputada a marca da barbárie por décadas. Por esse motivo, a autora aponta que o evento de 1922 foi um marco no que diz respeito ao estabelecimento de uma diplomacia cultural que contemplasse os países americanos e que avançasse na construção de um passado comum aos povos do chamado Novo Mundo. (GUIMARÃES, 2005, p. 194)

Em sua fala no Primeiro Congresso Internacional de História da América, Max Fleiuss, secretário perpétuo do IHGB, ressaltava que diante da crise enfrentada pela Europa no período pós-guerra, a América aparecia aos olhos do mundo como um exemplo de solidariedade intercontinental. (SILVA, 2019, p. 195-196)

O ensino, principalmente da disciplina História, foi enxergado nesse contexto como elemento-chave na promoção da paz entre os países. A concepção que se difundiu no mundo europeu no período pós-guerra defendia que as histórias nacionais, da forma que eram ensinadas anteriormente, ensejavam o ódio entre as nações e o belicismo. Surgiram comissões internacionais e congressos que buscavam analisar os conteúdos pedagógicos e sugerir modificações, caso fossem constatadas agressões, no ensino adotado nesses países, a nações estrangeiras. Em vários eventos foram apresentadas propostas para a promoção da solidariedade internacional..$^{5}$ (RIEMENSCHNEIDER, 1984)

Apesar das falas que rechaçavam a Europa como modelo a ser seguido na década de 1920, nos anos 30 a tendência internacional de rever os programas e manuais de ensino foi seguida pelos governos do Brasil e da Argentina, que assinaram acordos e convênios com essa finalidade. (Cf. SANTOS, 2009 e RODRIGUES, 2017)

\footnotetext{
${ }^{5}$ Luís Reznik oferece vários exemplos, dos quais destacamos alguns: - Sociedade das Nações (Assembléia, Conselho, Comissão de Cooperação Intelectual, Sub Comitê de Peritos para ensinar às crianças e aos jovens sobre a existência e os fins da Sociedade das Nações), 1923 em diante; União Internacional de Sociedades da Paz, Bale, 1923; Congresso Internacional de ciências históricas, Oslo, 1928; Congresso da paz pela escola, Praga, 1927; Congresso internacional para a revisão dos erros históricos contidos nos manuais de ensino de História, Haya, 1932; Conferência Internacional para o ensino de História, Basiléia, 1934. Cf: REZNIK, 1992)
} 
Em 1933, aproveitando a visita do presidente da República Argentina, General Agustin P. Justo, foi firmado pelo governo brasileiro, juntamente ao governo argentino, um convênio para revisão dos textos de História e Geografia. O objetivo era retificar os textos adotados no ensino dessas disciplinas nos dois países, com vistas a depurar os chamados manuais de ensino de referências que pudessem fomentar "a aversão a qualquer povo americano". (HOLLANDA, 1957, p. 204) Era necessário formar as futuras gerações para o desenvolvimento de relações cordiais com o país vizinho. (SILVA, 2011, p. 272274)

O convênio foi oficializado em decreto apenas em 1934 e somente em 1936 foi publicado um documento do Ministério das Relações Exteriores constituindo a Comissão Brasileira Revisora dos Textos de História e Geografia. Juçara Luzia Leite aponta que cabe ressaltar a atuação do Ministério das Relações Exteriores do Brasil na regulamentação de um ensino de História que repercutisse a atuação de intelectuais, entendidos pela autora como políticos e professores, engajados na construção da imagem do país como pacífico e civilizado perante as outras nações. (LEITE, 2011, p. 81)

Durante muito tempo, apenas por meio da correspondência, pessoas fisicamente distantes poderiam intercambiar ideias e manifestações de afeição, debater planos, idealizar projetos conjuntos, entabular negócios, fazer combinações, estruturar ações ou mesmo encetar polêmicas e altercações. Por esse motivo, Giselle Venâncio afirma que "a correspondência pessoal de um indivíduo é (...) um espaço definidor e definido pela sua sociabilidade.” (VENANCIO, 2001, p. 32)

A correspondência entre Ricardo Calmon e Pedro Levene era de cunho estritamente profissional e foi importante para o desenvolvimento dos projetos das comissões mencionadas e das coleções de autores traduzidos que teriam lugar na segunda metade da década de 1930 no Brasil e na Argentina. Das cartas enviadas por Levene a Calmon, uma é datada de 1935, uma de 1936, quatro de 1937, nove de 1938, duas de 1939, duas de 1941 e uma de 1943. De maneira geral, as missivas dão conta do andamento das iniciativas de cooperação entre os seus países de origem e de solicitações de envio de materiais e referências. 
A primeira carta de Levene a Calmon, encontrada no fundo do intelectual brasileiro foi escrita em papel timbrado do Ministerio de Justicia e Instruccion Pública de la Nación Argentina e traz ainda o carimbo da Comisión Revisora de Textos de Historia y Geografia. A carta é datada de 16 de novembro de 1935 e nela Levene, dirigese a Calmon como "miembro del ilustre Instituto Histórico y Geográfico de Rio de Janeiro", instituição com a qual estabelecera e mantinha relações no Brasil.

A comissão argentina fora criada em julho de 1935. O argentino enviou ao brasileiro uma cópia das Proposições adotadas pela Comissão Revisora de seu país, aprovadas pelo Ministro de Justiça e Instrução Pública. Pedia ainda notícias do andamento dos trabalhos da comissão revisora brasileira. Assina a missiva como "Presidente" da comissão argentina. (BR BACMB PC TXT CP 23_4179)

Também na Argentina, ao longo das décadas de 1920 e 1930, desenvolve-se uma concepção pacifista a respeito da História. Alguns eventos motivaram esse desenvolvimento como a instituição da comemoração, a partir do ano de 1917, do Dia de la Raza e o estabelecimento da Semana da América, originada pela V Conferência PanAmericana, que teve lugar no Chile, em 1923, bem como realização do Terceiro Congresso Americano da Criança, que ocorreu no Rio de Janeiro, em 1922. (CORDEIRO, 2015)

Nesses eventos, optou-se por criar cadeiras nos programas de ensino com o intuito de difundir entre os estudantes sentimentos de cordialidade e fraternidade americanas. A ideia era no lugar da história nacional, ensinar história da civilização, pois, dessa forma, poderia-se vislumbrar o progresso da humanidade como um todo. (SILVA, 2011, p. 281) Essa tendência também foi divisada no Brasil, a partir de 1931, com a Reforma de Ensino de Francisco Campos, que extinguiu nos programas de ensino do curso secundário as cadeiras de História Universal e História do Brasil, criando em seu lugar a cadeira de História da Civilização. (REZNIK, 1992)

Em primeiro de abril de 1935, José Carlos Macedo Soares, Ministro das Relações Exteriores, recebera um memorandum de Monis de Aragão, secretário geral do Itamaraty, apontando a urgência de organizar uma comissão para a revisão dos textos de História e 
Geografia, em cumprimento ao convênio celebrado entre o Brasil e a Argentina, por ocasião da visita do Presidente Justo ao Rio de Janeiro, em 1933. O Presidente do Brasil, Getúlio Vargas também visitara a Argentina, em 1935.

O secretário aponta que o governo argentino, em cumprimento ao acordo, já havia organizado a sua comissão, formada pelos professores Ricardo Levene, Frederico A. Daus, Carlos Correa Luna, Emilio Ravignani e Felix S. Ontes. Sugere então alguns nomes para a composição da referida comissão, dentre os quais Carlos Delgado de Carvalho, Jonathas Serrano e Pedro Calmon. Esses nomes, segundo o secretário, foram sugeridos por Anísio Teixeira, Diretor Geral do Departamento de Educação do Distrito Federal. ${ }^{6}$

Anísio Teixeira esteve à frente da Secretaria de Educação do Distrito Federal entre os anos de 1931 e 1935. Continuando a política de pan-americanismo escolar inaugurada na década de 1920 na gestão de Carneiro Leão, o secretário inaugurou seis escolas que homenageavam países latino-americanos. ${ }^{7}$ Esperava-se que a criação de tais escolas promovesse a aproximação com os países designados, fomentando um sentimento de solidariedade entre os membros da comunidade escolar e os habitantes dos respectivos países. Raquel Paz dos Santos aponta que a experiência mais bem-sucedida nesse sentido foi a da escola Argentina, que se tornou uma escola "experimental" na então capital brasileira. (SANTOS, 2009, p. 368)

Os dois primeiros nomes apontados por Teixeira para compor a comissão foram importantes figuras do campo educacional nos anos 1930 e 1940, tendo participado ativamente dos debates acerca da elaboração dos programas de ensino de História das reformas de Francisco Campos (1931) e Gustavo Capanema (1942). Eram professores do Colégio Pedro II e também autores de livros didáticos de História Geral e História do Brasil. (VALE, 2011)

\footnotetext{
${ }^{6}$ Correspondência Passiva, Doc. 7, Memorandum. Em 1. ${ }^{\circ}$ de abril de 1935. Convênio entre o Brasil e a Argentina para a revisão de textos de História e Geographia. Assinado por Monis de Aragão. (MOREIRA e BRANCATO, 2003, pp. 67-68)

${ }^{7}$ Foram as escolas Argentina, Honduras, México, Nicarágua, Paraguai e Venezuela. Atualmente, todas elas são administradas pela Prefeitura da cidade do Rio de Janeiro. (SANTOS, 2009 p. 368)
} 
A despeito dos esforços de Monis de Aragão e das cobranças de Levene, a comissão só se reuniu efetivamente pela primeira vez em 14 de maio de 1936, no Palácio do Itamaraty. (SILVA, 2011, p. 277)

Sua composição final contou com Affonso de Escragnole Taunay (Diretor do Museu Paulista), Emílio Fernandes de Sousa Doca (militar), Fernando Raja Gabaglia (Professor do Colégio Pedro II), Othelo Rosa (Secretário de Educação e Saúde do Rio Grande do Sul), José Carlos Macedo Soares (Ministro das Relações Exteriores), Jonathas Serrano (Professor do Colégio Pedro II) e Pedro Calmon. Quase todos os membros tinham ligação com o IHGB. (SILVA, 2011, p. 276)

Na sessão inaugural da comissão, Calmon apontou a necessidade de estender as proposições por esta fixadas a todos os estados do Brasil. Também recordou a necessidade de definição das bases da comissão o mais claramente possível, como havia sido feito pelos congêneres argentinos. Por fim, destacou que se deveria evitar a ênfase demasiada no ensino da história militar e privilegiar a história econômica. (SILVA, 2011, p. 276-277)

Ana Paula Barcelos da Silva (2011, p. 278) mostra que na ata da segunda sessão da comissão é relatado o envio de telegrama a Ricardo Levene comunicando-lhe a respeito do início dos trabalhos da comissão brasileira. O intelectual argentino escreveu em $27 \mathrm{de}$ maio do mesmo ano um telegrama agradecendo o aviso a respeito do início das atividades da comissão brasileira e exaltando o seu trabalho. (SILVA, 2011, p. 280)

Os intelectuais brasileiros e argentinos empenharam-se nos empreendimentos em seus respectivos países. Em três de junho de 1936, Calmon enviou um telegrama ao ministro Fonseca Hermes reportando correspondência recebida do argentino. Nela, Levene afirma a similaridade dos princípios orientadores das duas comissões. (SILVA, 2011, p. 280-281)

A última reunião da comissão brasileira para o estabelecimento das bases sobre as quais se daria a revisão ocorreu em 22 de maio de 1936. (SILVA, 2011, p. 279, nota 476) Nela foram registrados os princípios básicos que deveriam reger a revisão dos materiais de ensino de História e Geografia. 
Silva aponta que encontrou no material referente aos Acordos Internacionais, disponível no Arquivo Histórico do Itamaraty, cópia das bases apresentadas por Calmon para a revisão. (SILVA, 2011, p. 477) Renato Amado Peixoto afirma que as discussões levadas a cabo pela comissão brasileira se desenrolaram a partir de tais bases, que eram inspiradas na História da Civilização Brasileira, livro de Calmon publicado pela Companhia Editora Nacional, em 1933. O que leva o autor a concluir que a comissão foi liderada intelectualmente por Calmon. (PEIXOTO, 2016, p. 60 e p. 71) De fato, as "Normas" oficializadas pela Comissão Brasileira apresentam trechos idênticos às aludidas bases apresentadas por Calmon, o que indica que ele exercia uma liderança na comissão brasileira semelhante à que Levene exercia na Argentina. (HOLLANDA, 1957, p. 206-207)

A referida comissão funcionou por pouco tempo. A partir do decreto-lei de 1006, de 30 de dezembro de 1938, ficou estabelecida a criação da Comissão Nacional do Livro Didático (CNLD), subordinada aos Ministérios da Educação e Saúde. Dessa forma, o trabalho de revisão dos textos para o ensino de História e Geografia saía da alçada do Ministério das Relações Exteriores. (LEITE, 2011, p. 83-84)

Ainda em julho de 1936, o embaixador da Argentina no Brasil, Ramón Cárcano, escreveu ao Itamaraty comunicando a chegada de Levene ao Brasil no dia 25 do mesmo mês. O embaixador apresenta Levene como "entusiasta amigo del Brasil y sócio correspondiente del Instituto Histórico". A visita de Levene ao Brasil tinha o objetivo de acompanhar trabalhos da comissão e também firmar as bases para as traduções de obras de autores argentinos no Brasil e brasileiros na Argentina. (SILVA, 2011, p. 285)

Sua estadia no país se estendeu pelos meses de julho e agosto de 1936 e os intelectuais da Comissão Revisora se reuniram com ele em agosto para acertar a constituição da Biblioteca de Autores Brasileiros traduzidos ao Castelhano e da Coleção Brasileira de Autores Argentinos. 


\section{Dos convênios de tradução às bibliotecas de autores}

Por ocasião de sua visita ao Brasil, em 1936, Ricardo Levene anunciou que o governo Justo havia aberto crédito para a tradução para a língua espanhola e impressão, no mesmo ano, de duas ou três obras representativas da literatura brasileira. Affonso Taunay também anunciou que o governo brasileiro financiaria a tradução de duas obras argentinas. Comprovando a suposição de que Pedro Calmon exercia uma liderança na comissão brasileira, tal qual Levene na comissão argentina. Os dois primeiros livros aprovados para constituírem as bibliotecas que se desejava criar foram justamente Historia de la Civilización Argentina, de Levene, e a já mencionada História da Civilização Brasileira, de Calmon, que não participava da reunião por estar em viagem. (SILVA, 2011, p. 285)

O livro de Calmon fora lançado como volume da coleção Brasiliana da Companhia Editora Nacional em 1933 e alcançara um relativo sucesso editorial, sendo sua segunda edição lançada já em 1935. Nos catálogos da editora o livro era recomendado como uma "obra confiável pela utilização rigorosa do método científico, pela análise segura da formação histórica do povo brasileiro e pelas sugestões sobre o Brasil". (DUTRA, 2006, p. 308)

Na década de 1930, como parte das iniciativas empresariais de modernização e afirmação de um mercado do livro no Brasil, diversas editoras lançaram coleções destinadas a discutir temas nacionais. A subsérie Brasiliana da coleção Biblioteca Pedagógica Brasileira (BPB), publicada pela Companhia Editora Nacional, foi a pioneira e tornou-se a mais conhecida, servindo de referência genérica às coleções criadas por outras editoras, que também ficaram conhecidas como "brasilianas". (GOMES, 2014, p. 6) O termo passou a designar toda coleção ou conjunto de livros que deveriam ser lidos para se conhecer o Brasil, uma alusão a uma "biblioteca" que possibilitasse uma visão geral de toda a cultura nacional. (SORÁ, 2010, p. 28)

Baseando-se em dados de registros do Movimento das Edições da Companhia Editora Nacional, Eliana de Freitas Dutra mostra que enquanto a média das edições da 
Brasiliana era de 2.000 exemplares por edição, a História da Civilização Brasileira teve em sua primeira e segunda edições a tiragem de 10.000 exemplares. Um sucesso editorial para os padrões da época. (DUTRA, 2006, p. 309)

Encorajado por esse sucesso, Pedro Calmon propôs a tradução para o castelhano e publicação de seu livro na Colección Labor ${ }^{8}$ aos Diretores da Editorial Labor S. A., situada em Barcelona. (BR BACMB PC TXT CP 12_4992) Calmon salientava que o seu livro era único com esse título e que atendia "à nova índole dos compêndios históricos". A "nova índole" referida por Calmon dizia respeito à nomenclatura que havia sido adotada a partir da já mencionada reforma do ensino secundário de Francisco Campos, instituída em 1931. A História do Brasil seguiu a nomenclatura, estabelecendo-se como História da Civilização no Brasil ou História da Civilização Brasileira. (FERREIRA, 2013, p. 28-32)

Não foi encontrada a resposta para a carta, mas por ela se pode ter ideia de que Calmon buscava que sua obra fosse incluída no catálogo de uma editora internacional, em uma coleção reconhecida por publicar livros técnicos e científicos destinados ao público universitário, visando conferir-lhe visibilidade. A oportunidade surgiu dois anos depois da escrita da carta à editora espanhola, por meio do referido convênio firmado entre o governo brasileiro e o governo argentino.

Ao tratar a questão das traduções, Gustavo Sorá (2003, p. 18) afirma que o estudo acerca da seleção de obras a serem traduzidas nos permite compreender a racionalidade por trás das alianças internacionais estabelecidas pela difusão de um livro em território estrangeiro. A recepção favorável, ou não, que um livro encontra contribui para compreender os significados adquiridos pelo texto a partir de sua circulação. O livro de Calmon, nos anos seguintes à sua publicação, não encontrou eco na Espanha, mas sim na Argentina. Sua tradução e incorporação à Biblioteca de Autores Brasileños traducidos al castellano mostra que o momento era propício para a divulgação do tipo de conteúdo que portava no país vizinho.

\footnotetext{
${ }^{8}$ A Editorial Labor era especializada em livros científicos e técnicos. A Colección Labor chegou a publicar mais de 400 títulos. (SOUSA, 2005, p. 63) 
Da mesma forma que Levene veio ao Brasil, para tratar de assuntos relacionados aos convênios de tradução e publicação de livros, Calmon também foi à Argentina no mesmo ano. Pelo menos é o que afirma a carta de Afonso Taunay a Ricardo Levene, datada de 21 de novembro de 1936. A carta menciona a conversa de Levene com Calmon quando este esteve em Buenos Aires, sem fazer referência à data, entretanto, pela palavra "agora" percebe-se que sua visita se deu em data recente à da carta. Decerto, Levene estava preocupado com o andamento dos trabalhos da coleção brasileira. Taunay afirma nada saber a respeito do andamento dos projetos de intercâmbio, mas declara ter certeza que Calmon "está fazendo toda força para quanto antes, vermos sahir os primeiros volumes das duas series, quero dizer da serie brasileira”. (Carta de A. de Taunay a Ricardo Levene, 21 de novembro de 1936)

Em carta enviada no dia 28 do mesmo mês, Taunay afirma ainda não ter notícias diretas de Calmon, mas diz que espera que o Dr., que acredito se tratar de Levene, ao encontrar-se com Macedo Soares, "dê um bom avanço a nossa projetada biblioteca, brasileiro-argentina". (Carta de Affonso de E. Taunay a Ricardo Levene, 28 de novembro de 1936)

O interesse de Levene parecia ser grande em relação ao empreendimento, tanto que ainda em 31 de dezembro de 1936 escreve diretamente a Calmon lembrando que na última carta solicitara o envio de um mapa do Brasil para incorporá-lo ao seu livro, que já estava traduzido por Julio Payró para o castelhano e "composto integralmente". Na mesma carta, afirma que em breve mandará sua obra Síntese sobre la historia de la civilización argentina reelaborada e pede que Calmon dê o consentimento para fazer alterações no texto, tendo em vista a consecução dos ideais de verdade e cordialidade, uma vez que, em seu entendimento, as alterações sugeridas eram puramente de forma. A carta é seguida das sugestões de mudança na redação de alguns trechos do livro. (BR BACMB PC TXT CP 23_17065)

A correspondência, nesse caso, busca a autorização de Calmon para fazer alterações no texto, de forma que Levene preparasse a obra para os leitores argentinos, buscando antecipar a recepção, de forma a garantir uma aceitação por parte dessa 
audiência imaginária. Embora essa antecipação não se dê propriamente no terreno da correspondência, cabe citar um trecho da obra de Geneviève Haroche-Bouzinac (2016, p. 165), no qual ela aponta que em algumas circunstâncias

\begin{abstract}
a carta se torna um terreno de experimentação em que o destinatário vale como exemplo do público futuro. Busca-se conhecer-lhe o gosto, não só para escrever atendendo às expectativas, como também para evitar críticas. Fazer com que leitores privilegiados participem da criação é uma forma de garantir apoio e audiência por parte deles. (HAROCHE-BOUZINAC, 2016, p. 165)
\end{abstract}

A intensificação da correspondência entre Levene e Calmon nos anos de 1937 e 1938 se deu por ocasião das providências requeridas acerca das publicações das respectivas séries de publicações.

Calmon responde à referida carta de Levene do final de 1936 em fevereiro de 1937, afirmando estar de acordo com as sugestões feitas para adequar o livro ao espírito de cordialidade que se buscava:

\begin{abstract}
Agradecendo as suas bôas sugestões sobre a nova redacção que alvitra para vários trechos da minha HISTORIA DA CIVILIZAÇÃO BRASILEIRA, declaro estar de inteiro acordo com essas modificações propostas, e as autorizo. Reconheço, proclamo e corroboro os objectivos de intima e sincera cordialidade internacional, implícitos no trabalho que vimos realizando de revisão de textos. Demos, pois, o exemplo. Seria imperdoavel que em livro traduzido com esse espírito perdurasse qualquer traço contrário à nossa cruzada. O meu querido amigo tem plenos e amplos poderes, sem reserva nenhuma para modificar a redacção onde julgar conveniente. (Carta de Pedro Calmon a Ricardo Levene, 12 de fevereiro de 1937)
\end{abstract}

Pela resposta de Calmon, pode-se notar que Levene não apenas faz sugestões pontuais para a obra a ser traduzida, como também sugere modificações de "vários trechos" do livro, sob a justificativa de adequá-lo aos objetivos do projeto de cordialidade internacional ao qual o convênio de tradução estava vinculado. Mais que um leitor privilegiado futuro, Levene atua no sentido de modificar a redação de Calmon, de forma a evitar possíveis críticas, antecipando as expectativas dos agentes envolvidos no empreendimento das coleções de autores traduzidos. Se o conteúdo deveria estar adequado, a apresentação também se fazia importante. 
A Biblioteca de Autores Brasileños Traducidos ao Castellano se iniciou no mesmo ano com a publicação de Historia de la Civilización Brasileña, de Pedro Calmon. Sorá afirma que pelo seu formato, a coleção se assemelhava à Brasiliana, da Companhia Editora Nacional. Entre 1933 e 1943, Pedro Calmon foi o autor mais publicado pela Brasiliana, com um total de nove títulos lançados. Todos os autores publicados pela coleção argentina foram publicados pela Brasiliana ou pela coleção Documentos Brasileiros da Livraria José Olympio. (SORÁ, 2003, p. 122)

Enquanto a Biblioteca de Autores Brasileños Traducidos ao Castellano teve seus primeiros volumes publicados ao longo de 1937, a Biblioteca de Autores Argentinos Traduzidos ao Português não teve a mesma sorte. Em carta de 18 de junho de 1938, Levene acusa o recebimento de correspondência de Pedro Calmon, na qual o intelectual brasileiro dá a notícia de que o Ministro das Relações Exteriores, Oswaldo Aranha havia autorizado a publicação de três volumes de "autores argentinos traducidos al Portugues". O argentino parece denotar certa impaciência, ao afirmar ao brasileiro: “impression muy favorable ha producido esta resolución". (BR BACMB PC TXT CP 23_17059)

Afirma ainda esperar que se possa publicar sua obra Historia de la Civilización Argentina [sic] com o grande prólogo escrito por Pedro Calmon. Aponta que a obra Historia de la Civilización Brasileña tem sido distribuída em todo o seu país e a América Espanhola, tendo logrado êxito em toda parte. É preciso reconsiderar a afirmação de Levene, pois Sorá ao pesquisar sobre a coleção recentemente, mostra que se o apoio do governo possibilitou a circulação dos livros, que eram distribuídos gratuitamente a escolas, instituições culturais, jornais, revistas e intelectuais, por outro lado, o autor aponta que sua distribuição pelo Estado poderia ter prejudicado a recepção da coleção. Sorá chega a essa conclusão baseando-se na dificuldade de recuperação dos volumes em sebos e bibliotecas e a partir do baixo índice de citações em estudos sobre o Brasil e afirma que, apesar do apoio estatal, ou mesmo por causa dele, os exemplares dificilmente teriam sido absorvidos pelos circuitos comerciais. (SORÁ, 2003, p. 120-121)

Levene sugere ainda na missiva que o segundo volume da Biblioteca de Autores Argentinos seja Facundo de Sarmiento, pois em setembro do mesmo ano se cumpriria o 
cinquentenário da morte do autor. Propõe a publicação como uma homenagem, pois em comemoração à data teriam lugar na Argentina e em outros países da América atos e conferências celebrando a memória do autor. (BR BACMB PC TXT CP 23_17059)

Ao que parece, os planos de publicação andaram depressa. Em 30 de julho de 1938, uma nova carta de Levene é endereçada a Pedro Calmon. Nela, Levene afirma concordar com a supressão de alguns capítulos de Historia de la Civilización Argentina, para que a publicação fosse feita em volume único. Dá notícias ainda de que o livro Pedro II e o Instituto Histórico, de Afonso Celso, já estava pronto para publicação. O volume seria publicado como uma homenagem ao centenário do Instituto e ao seu presidente, que acabara de falecer. (BR BACMB PC TXT CP 23_17057)

Abaixo, podemos visualizar a tabela dos livros publicados pela Biblioteca de Autores Brasileños traducidos al castellano, segundo levantamento feito por Gustavo Sorá (2002, p. 196).

Tabela 1 - Biblioteca de Autores Brasileños traducidos al castellano

\begin{tabular}{|l|c|c|}
\hline \multicolumn{1}{|c|}{ Título } & Autor & Ano \\
\hline Historia de la Civilización Brasileña & Pedro Calmon & 1937 \\
\hline Evolución del Pueblo Brasileño & Oliveira Vianna & 1937 \\
\hline El emperador D. Pedro II & Afonso Celso & 1938 \\
\hline Los sertones & Euclides da Cunha & 1938 \\
\hline Conferencias y Discursos & Rui Barbosa & 1939 \\
\hline Mis Memorias de los Otros & Rodrigo Octavio & 1940 \\
\hline Casa Grande \& Senzala & Gilberto Freyre & 1942 \\
\hline Pequeña Historia de la Literatura Brasileña & Ronald de Carvalho & 1943 \\
\hline San Pablo en el Siglo XVI & Afonso d'E. Taunay & 1947 \\
\hline La vida en la Selva & Cândido de Melo Leitão & 1949 \\
\hline
\end{tabular}


Pode-se perceber que enquanto na coleção argentina foram publicados quatro volumes nos anos de 1937 e 1938, dentre eles o anunciado livro de Afonso Celso, a coleção brasileira ainda não saíra do papel. A maior preocupação de Levene parece ser com as efemérides que estavam deixando de ser comemoradas por conta da morosidade da coleção brasileira em publicar os seus primeiros volumes, como o cinquentenário da morte de Sarmiento.

No canto da missiva, de forma privada, "como amigo", Levene pede quase como uma súplica para que Calmon apressasse a publicação dos primeiros volumes em português da coleção, ainda que não fosse o seu livro o primeiro a ser publicado. Antes, preferia que se editassem as obras de Sarmiento e Bartolomeu Mitre. Talvez, no entendimento do intelectual, grandes oportunidades de reconhecimento mútuo entre os dois países em torno das comemorações estariam sendo perdidas, ou havia uma cobrança por parte do governo argentino nesse sentido. Levene afirma ser necessário um homem como Calmon, com seu ímpeto e cultura, para que se pudesse levar adiante "esta obra de solidaridad intelectual”. (BR BACMB PC TXT CP 23_17057)

Ao investigar as coleções editoriais francesas no século XIX, Isabelle Olivero as denomina como "bibliotecas". A autora mostra que elas possuíam a missão "civilizadora" de educar, instruir, formar o "homem e o cidadão". Investidas de um papel social, educativo, político e econômico, as coleções eram destinadas a públicos específicos. Sua composição e organização implicavam a seleção de volumes em um universo de todos os livros possíveis, que estivessem de acordo com a ideia de criação de uma "biblioteca ideal". (OLIVERO, 1999, p. 267)

Incorporar um escrito em uma coleção implicava definir um público alvo, pelo menos pretensamente, e o entendimento de que o escrito se adequava a um projeto intelectual e a um propósito educacional. Os livros agregados às coleções compunham um produto editorial elaborado coletivamente e como tal deveriam refletir a concepção conjunta do projeto. Para os idealizadores de tais coleções, o livro e a leitura seriam instrumentos da cultura e serviriam ao aperfeiçoamento espiritual e moral e ao enriquecimento da consciência. (OLIVERO, 1999, p. 269) 
Nos projetos de bibliotecas arquitetados pelos governos brasileiro e argentino e viabilizados por Levene e Calmon, a missão civilizadora de instruir para a cordialidade e o estabelecimento de boas relações entre os dois países passava necessariamente por fazer o outro conhecer suas respectivas histórias nacionais, fundamentadas sob as bases da revisão. O próprio Levene ressalta a palavra "revisão" no prólogo que escreveu ao livro de Calmon. Segundo ele: "estamos revisando lo hecho anteriormente para ampliarlo en unos casos, para olvidar en otros, para vivificar las verdades del pasado trayéndolas al presente en todos los casos, levantando el sentimiento público". (LEVENE, 1937, p. 9)

Fazia-se necessário revisar as histórias nacionais assentando-as em novas bases que não fossem ofensivas ao país vizinho. Uma história nacional que se pautasse não nas diferenças e divergências em relação aos outros países americanos, mas no que os unia e aproximava. Era preciso negar, no caso brasileiro, pelo menos naquele momento específico, toda uma construção que vinha desde o século XIX e que esteve presente desde a fundação do Instituto Histórico e Geográfico Brasileiro, que ressaltava as diferenças do caso brasileiro em relação aos outros países da América. Fazia-se necessário apresentar a história argentina aos brasileiros, como forma de recuperar o intervalo de um século em que a história do Brasil estivera voltada para si, mirando a Europa e dando as costas para o resto da América.

No século XIX, a figura do editor ganhou autonomia e se consolidou tal como a conhecemos atualmente. Essa atividade passou a ser desempenhada por pessoas capazes de aliar as características intelectuais às comerciais no desempenho de tarefas que incluíam obter textos para publicação, selecionar autores e monitorar o processo editorial desde a produção da obra até sua distribuição. (CHARTIER, 1998, p. 50)

Chartier afirma que os editores desempenharam um papel fundamental “inventando as fórmulas capazes de associar repertório textual e capacidade produtiva". (CHARTIER, 2002, p. 75) Munido de suas experiências, habilidades, relações pessoais e profissionais, e informado por suas convicções e preferências, o editor "filtrava" o que chegaria aos leitores a partir de sua própria avaliação. (DARNTON, 2010, p. 14) Para 
Olivero, o editor se engajava em transformar o mundo por meio de seu trabalho. (OLIVERO, 1999, p. 270)

Pode-se perceber que enquanto editores das duas coleções, Calmon e Levene possuíam expectativas diferentes para as coleções das quais se incumbiram da função editorial. Possivelmente, para Calmon a prioridade era fazer conhecer aos brasileiros a história argentina, enquanto que para Levene, a prioridade era contemplar por meio das coleções as celebrações que julgava importantes para o fomento das relações de cordialidade. A maneira que os dois autores-editores encontraram para conciliar suas ambições foi a troca de correspondências.

A Síntese da História da Civilização Argentina foi finalmente publicada no final de 1938, com o longo prefácio almejado por Levene assinado por Pedro Calmon. Nele Calmon afirma que:

\begin{abstract}
Os povos americanos temos sobre os outros continentes a vantagem de uma evolução social que nos dá a impressão de simétricas ou idênticas vicissitudes, dos mesmos dramas, de iguais sacrifícios e heroísmos, unidos no tempo, pelo hercúleo trabalho de criação nacional, como estamos unidos no espaço, pelos lindes territoriais. Ao contrário do que se vê alhures, na América a história não se separa, porém vincula as nações (...) As metrópoles projetaram, é certo, a inquietante sombra de suas querelas sobre o mapa sul-americano: mas nas síncopes de seu intervencionismo brotava - rude flor de terreno virgem - a espontânea ideia de integração continental. (CALMON, 1938, p. 7-8)
\end{abstract}

Raquel Paz dos Santos mostra que a coleção Coleção Brasileira de Autores Argentinos foi publicada até 1951, tendo lançado nove volumes, todos traduzidos por J. Paulo de Medeyros. A lista abaixo dos volumes publicados foi feita com base no levantamento da autora. (SANTOS, 2009, p. 365). 
Tabela 2 - Coleção Brasileira de Autores Argentinos

\begin{tabular}{|l|c|c|}
\hline \multicolumn{1}{|c|}{ Título } & Autor & Ano \\
\hline $\begin{array}{l}\text { Síntese da história da civilização } \\
\text { argentina }\end{array}$ & Ricardo Levene & 1938 \\
\hline De Caseros ao 11 de setembro & Ramón J. Cárcano & 1939 \\
\hline Orações seletas & Bartolomeu Mitre & 1940 \\
\hline Bases & Juan B. Alberti & 1941 \\
\hline Vidas argentinas & Octavio Amadeo & 1942 \\
\hline Seis figuras do Prata & Juan P. Echagüe & 1946 \\
\hline O santo da espada & Ricardo Rojas & 1948 \\
\hline Mitre & Rodolfo Rivarola & 1950 \\
\hline Recordações de província & Sarmiento & 1951 \\
\hline
\end{tabular}

Pela comparação das listas, pode-se visualizar que na década de 1930, a coleção argentina publicou um total de cinco volumes, enquanto a brasileira publicou apenas dois. Em relação à coleção brasileira, os cinco primeiros volumes foram publicados um a cada ano de 1938 a 1942.

Na década de 1940 ambas as coleções sofrem um hiato. A brasileira não é publicada entre os anos de 1943 e 1945 e a argentina deixa de ser publicada entre 1944 e 1946. Esse hiato provavelmente pode ser explicado por ocasião da Segunda Guerra Mundial (1939-1945), que suscitou diferentes posicionamentos no continente. O conflito talvez tenha deitado por terra as esperanças dos que acreditavam que a promoção da paz por meio do ensino e da escrita da História ainda se fazia possível. 


\section{Considerações finais}

Este artigo buscou analisar as relações entre os intelectuais Pedro Calmon e Ricardo Levene por meio de correspondências trocadas entre eles. Acredita-se que, diferentemente dos documentos oficiais do Ministério das Relações Exteriores brasileiro, que têm por objetivo apresentar ações consolidadas, a correspondência é um terreno fértil para investigar as incertezas, as indefinições e os obstáculos no delineamento de tais projetos.

Os projetos tratavam-se das comissões de revisão de textos de ensino, sobretudo de História e Geografia, que tiveram lugar nos países de origem dos intelectuais e sobretudo, das bibliotecas de autores traduzidos: a Biblioteca de Autores Brasileños traducidos al castellano e a Coleção Brasileira de Autores Argentinos. Espera-se que tenha sido possível mostrar que as correspondências podem nos indicar caminhos para atingir "ideias, projetos, opiniões, interesses e sentimento" (GOMES, 2004, p. 51-52) que foram expurgados dos livros publicados, nos quais não há espaço para as incertezas, os conflitos, as mudanças de percurso e os fracassos.

Calmon e Levene foram capazes de transitar entre o domínio da escrita da História e o campo político, atuando como "mediadores". Possibilitaram diálogos culturais e intelectuais entre os seus respectivos países, atuando como editores das coleções de tradução de autores, que são denominadas nos trabalhos historiográficos que se debruçaram sobre essas questões como "coleções oficiais", pois foram chanceladas subsidiadas pelos governos brasileiro e argentino na década de 1930.

A despeito das diferenças de expectativas verificadas na forma de conduzir as coleções que organizavam e que ficaram claras por meio da correspondência, os dois autores promoveram e protagonizaram diálogos importantes entre Brasil e Argentina. Garantiram ainda aceitação no exterior para suas obras, que foram veiculadas nos países vizinhos como representativas das histórias brasileira e argentina, por meio da tentativa de consolidar "bibliotecas" de "livros que deveriam ser lidos" para conhecer os seus países de origem. 
Apesar de tais coleções não terem alcançado a projeção almejada nos países aos quais se destinavam, a investigação sobre elas é importante para materializar e humanizar as relações culturais e intelectuais entre Brasil e Argentina.

\section{Referências Bibliográficas}

\section{Fontes:}

BR BACMB PC TXT CP 12_4992. Fundação Pedro Calmon. Centro de Memória da Bahia. Carta de Pedro Calmon aos Diretores de Editorial Labor S.A. Data: 4 de abril de 1934.

BR BACMB PC TXT CP 23_4179 Fundação Pedro Calmon. Centro de Memória da Bahia. Carta de Ricardo Levene a Pedro Calmon. Data: 16 de novembro de 1935.

BR BACMB PC TXT CP 23_17065 Fundação Pedro Calmon. Centro de Memória da Bahia. Carta de Ricardo Levene a Pedro Calmon. Data: 31 de dezembro de 1936.

BR BACMB PC TXT CP 23_17059 Fundação Pedro Calmon. Centro de Memória da Bahia. Carta de Ricardo Levene a Pedro Calmon. Data: 18 de junho de 1938.

BR BACMB PC TXT AA 05_4200 Fundação Pedro Calmon. Centro de Memória da Bahia. Carta de Ricardo Levene a Pedro Calmon. Data: 4 de julho de 1938.

BR BACMB PC TXT CP 23_17057 Fundação Pedro Calmon. Centro de Memória da Bahia. Carta de Ricardo Levene a Pedro Calmon. Data: 30 de julho de 1938.

CALMON, Pedro. Prefácio. In: LEVENE, Ricardo. Sintese da História da Civilização Argentina. Rio de Janeiro: Ministério das Relações Exteriores, 1938. p. 7-11.

Carta de A. de Taunay a Ricardo Levene. Carta de agradecimiento y aviso de envío de libros. Arquivo Ricardo Levene. Biblioteca Nacional de Maestros. San Pablo, 21 de noviembre de 1936.1 Disponível em: <http://www.bnm.me.gov.ar/catalogo/Record/000121626> Acesso em 9 abr 2019

Carta de Affonso de E. Taunay a Ricardo Levene. Carta anunciando envío de libros. Arquivo Ricardo Levene. Biblioteca Nacional de Maestros. San Pablo, 28 de noviembre de 1936. Disponível em: <http://www.bnm.me.gov.ar/catalogo/Record/000121622> Acesso em 9 abr 2019 
Carta de Pedro Calmon a Ricardo Levene. Carta sobre producción de trabajos. Arquivo Ricardo Levene. Biblioteca Nacional de Maestros.. Río de Janeiro, 12 de febrero de 1937. Disponível em: <http://www.bnm.me.gov.ar/catalogo/Record/000121658> Acesso em 11 abr 2019

LEVENE, Ricardo. Prólogo. In: CALMON, Pedro. Historia de la civilizacion brasileña. Buenos Aires: Ministerio de Justicia e Instruccion Publica, 1937. p. 9-16.

\section{Bibliografia}

BAGGIO, Kátia Gerab. Apresentação. Varia História [online]. 2014, vol.30, n.54 (Acesso em 21-08-2020), pp.599-603. Disponível em: <http://www.scielo.br/scielo.php?script=sci_arttext\&pid=S0104https://doi.org/10.1590/S0104-87752014000300001.

BEIRED, José Luís Bendicho. O hispano-americanismo historiográfico: Espanha e América na perspectiva de Ricardo Levene e Rafael Altamira. História, Unisinos, v. 13, n. ${ }^{\circ} 1$, jan./abr. 2009. p. 43-53.

BOURDIEU, Pierre. A causa da ciência: como a história social das ciências sociais pode servir ao progresso das ciências. Revista Política e Sociedade. n. ${ }^{\circ}$, setembro de 2002, p. 143-161.

CASTRO, Fernando Luiz Vale. Pensando um continente: A Revista Americana e a criação de um projeto cultural para a América do Sul. Tese (Doutorado em História). Rio de Janeiro: Pontifícia Universidade Católica do Rio de Janeiro, 2007.

CHARTIER, Roger. A aventura do livro: do leitor ao navegador: conversações com Jean Lebrun. Trad. Reginaldo Carmello Corrêa de Moraes. São Paulo: Imprensa Oficial; Editora UNESP, 1998.

2002.

Os desafios da escrita. Trad. Fulvia M. L. Moretto. São Paulo: Editora UNESP,

CORDEIRO, Andréa Bezerra. Luz e caminho aos pequenos: os primeiros congressos americanos da criança e a pan-americanização dos saberes sobre a infância (1916-1922). Tese (Doutorado em Educação). Curitiba: Universidade Federal do Paraná, 2015.

DARNTON, Robert. A questão dos livros: presente, passado e futuro. Trad. Daniel Pellizzari. São Paulo: Companhia das Letras, 2010. 
DUTRA, Eliana de Freitas. A nação nos livros: a biblioteca ideal na coleção Brasiliana. In: DUTRA, Eliana de Freitas e MOLLIER, Jean-Yves (Orgs.). Política, nação e edição: o lugar dos impressos na construção da vida política. Brasil, Europa e Américas nos séculos XVIII-XX. São Paulo: Annablume, 2006. pp. 299-314.

Projetos editoriais e exposições do livro no espaço latino-americano: intelectuais e trocas culturais: 1930-1940 [en línea] Primer Coloquio Argentino de Estudios sobre el Libro y la Edición, 31 de Octubre, 1 y 2 de noviembre de 2012, La Plata, Argentina. Disponible em: <http://www.memoria.fahce.unlp.edu.ar/trab_eventos/ev.1928/ev.1928.pdf $>$ Acesso em 15 jun 2020

FERREIRA, Marieta de Moraes. A história como ofício: a constituição de um campo disciplinar. Rio de Janeiro: Editora FGV, 2013.

GOMES, Ângela de Castro. Em família: a correspondência entre Oliveira Lima e Gilberto Freyre. In: GOMES, Ângela de Castro (Org.). Escrita de si, escrita da História. Rio de Janeiro: Editora FGV, 2004. p. 51-75.

A República, a história e o IHGB. Belo Horizonte: Argvmentum, 2009.

GOMES, Ângela de Castro. Educação, ciência e edição: consagração intelectual dos periódicos às coleções. Revista Brasileira de História da Ciência, Rio de Janeiro, v. 7, n. 1, p. 6-15, jan -jun 2014.

e HANSEN, Patrícia. Apresentação. In: GOMES, Ângela de Castro e HANSEN, Patrícia (Orgs.). Intelectuais mediadores: práticas culturais e ação política. Rio de Janeiro: Civilização Brasileira, 2016. pp. 7-37.

GUIMARÃES, Lúcia Maria Paschoal. Um olhar sobre o continente: o Instituto Histórico e Geográfico Brasileiro e o Congresso Internacional de História da América. Revista Estudos Históricos, Rio de Janeiro, v. 10, n. 20, p. 217-230, dez. 1997. Disponível em: $<$ http://bibliotecadigital.fgv.br/ojs/index.php/reh/article/view/2057>. Acesso em: 29 Jun. 2020.

Limites políticos de um projeto intelectual para a integração dos povos do Novo Mundo: o Primeiro Congresso Internacional de História da América (1922). Topoi (Rio Janeiro, 2005, vol.6, n.10 p. 192-212. Disponível em: http://www.scielo.br/scielo.php?script=sci_arttext\&pid=S223701X2005000100192\&lng $=$ en\&nrm=iso. Acesso em 29 jun 2020 
HAROCHE-BOUZINAC, Geneviève. Escritas epistolares. Trad. Ligia Fonseca Ferreira. São Paulo: Edusp, 2016.

HOLLANDA, Guy de. Um Quarto de Século de Programas e Compêndios de História para o Ensino Secundário Brasileiro. 1931-1956. Rio de Janeiro: Centro Brasileiro de Pesquisas Educacionais. INEP - Ministério da Educação e Cultura, 1957.

LEITE, Juçara Luzia. Revisando livros didáticos de História: ação da diplomacia cultural em nome da paz. Revista Tempo e Argumento, [S.1.], v. 3, n. 2, p. 77 - 99, dez. 2011. ISSN 2175-1803. Disponível em: <http://www.revistas.udesc.br/index.php/tempo/article/view/2175180303022011077/17 89>. Acesso em: 29 jun. 2020.

LOPES, Maine Barbosa. Com dedicação e "espírito patriótico": a atuação de Ricardo Levene na Comisión Nacional de Museos y de monumentos y lugares históricos. Revista Tempos Históricos, Volume 21, 1. ${ }^{\circ}$ semestre de 2017, p. 385-409.

MOREIRA, Earle D. Macarthy e BRANCATO, Sandra Maria L. (Orgs.) O Arquivo de José Carlos de Macedo Soares: correspondência ativa e passiva selecionada. Porto Alegre: EDIPUCRS, 2003.

MYERS, Jorge Eduardo; El epistolario como conversación humanista: La correspondencia intelectual de Alfonso Reyes y Genaro Estrada 1916-1939; Centro de Documentación e Investigación de la Cultura de Izquierda en Argentina; Políticas de la memoria; $15 ; 11-2014$, p. 53-69

OLIVERO, Isabelle. L 'invention de la collection: De la diffusion de la littérature et des savoirs à la formation du citoyen au XIXe siècle. Paris: Editions de la Maison des Sciences de l'Homme, 1999.

PEIXOTO, Renato Amado. Moldando o corpo do Brasil: Jaime Cortesão, Rodrigo Octávio, a representação de Gusmão e o metajogo na região do Prata. História da Historiografia, Ouro Preto, n. 22, dezembro 2016. p. 59-78.

REZNIK, Luís. Tecendo o amanhã: A História do Brasil no Ensino Secundário:

Programas e Livros Didáticos. 1931 -1945. Dissertação (Mestrado em História). Niterói: Universidade Federal Fluminense, 1992.

RIEMENSCHNEIDER, Rainer. La confrontacion internationale des manuels. Contribuition au probleme des rapports. Entre manuel d'Histoire et memoire collective. Travaux du colloque Manuels d'Histoire et memoire collective. U.E.R. de Didatique des disciplines, Université de Paris 7, 1984. p. 127-140. 
RODRIGUES, João Paulo Coelho de Souza. Embaixadas originais: diplomacia, jornalismo e as relações Argentina-Brasil (1888-1935). Topoi, Rio de Janeiro, v. 18, n. 36, set./dez. 2017. p. 537-562.

SANTOS, Raquel Paz dos. Relações Brasil-Argentina: a cooperação cultural como instrumento de integração regional. Estudos Históricos, Rio de Janeiro, vol. 22, n. 44, julho-dezembro de 2009. p. 355-375.

SILVA, Ana Paula Barcelos Ribeiro da. Diálogos sobre a escrita da história: Brasil e Argentina (1910-1940). Brasília: Fundação Alexandre de Gusmão, 2011.

Max Fleiuss e Ricardo Levene: diálogos sobre o ibero-americanismo e a escrita da História no Brasil e na Argentina. Revista do Instituto Histórico e Geográfico Brasileiro, Rio de Janeiro, 173 (454), jan./mar. 2012. p. 209-236.

SILVA, Gabriela Correa da. Dos passados heterogêneos ao mosaico continental: panamericanismo e operação historiográfica no IHGB republicano (1889-1933). Tese (Doutorado em História). Porto Alegre: Universidade Federal do Rio Grande do Sul, 2019.

SIRINELLI, Jean François. Intelectuais. IN: RÉMOND, René. Por uma história política. Trad. Dora Rocha. 2 ed. Rio de Janeiro: Editora FGV, 2003. p. 231-269.

SORÁ, Gustavo. Livros de autores brasileiros na Argentina: uma força de alteridade negada. In: MARTINS, Maria Helena. (Org.) Fronteiras culturais: Brasil - Uruguai Argentina. Porto Alegre: Ateliê Editorial, 2002. pp. 171-208.

Traducir el Brasil: una antropologia de la circulación internacional de ideas. Buenos Aires: Livros del Zorzal, 2003.

Brasilianas: José Olympio e a gênese do mercado editorial brasileiro. São Paulo: Editora da Universidade de São Paulo: Com-Arte, 2010.

SOUSA, José Martínez de. Mi paso por Editorial Labor. Panace@ Vol. VI, n. ${ }^{19}$, Marzo, 2005. p. 63-67.

SUÁREZ, Carlos Alberto e SAAB, Jorge. El Estado, Ricardo Levene y los lugares de memoria. Clío \& Asociados (16), 2012, pp. 211-227. Disponible en:

http://www.memoria.fahce.unlp.edu.ar/art_revistas/pr.5550/pr.5550.pdf Acesso em 15 junho 2020. 
VALE, Nayara Galeno do. Delgado de Carvalho e o ensino de História: livros didáticos em tempos de reformas educacionais. Dissertação (Mestrado em História Social). Rio de Janeiro: Universidade Federal do Rio de Janeiro, 2011.

VENÂNCIO, Gisele. Presente de Papel: cultura escrita e sociabilidade na correspondência de Oliveira Vianna. Revista Estudos Históricos, Rio de Janeiro, v. 2, n. 28, p. 23-47, fev. 2001. ISSN 2178-1494. Disponível em: <http://bibliotecadigital.fgv.br/ojs/index.php/reh/article/view/2146>. Acesso em: 21 Ago. 2020. 